Малле Шмидт, Лия КРУМм, К. ЛЭЭТС

\title{
ИЗУЧЕНИЕ КИНЕТИКИ РЕАКЦИИ 1-ХЛОР-3-МЕТИЛ-5-ИЗОПРОП- ОКСИ-2-ПЕНТЕНА С N,N-ДИМЕТИЛФЕНИЛАМИНОМ
}

Ранее установлено, что первичные аллильные галогенопроизводные с $\mathrm{N}, \mathrm{N}$-диметилфениламином селективно превращаются в четвертичные аммониевые соли $\left[{ }^{1,2}\right]$. Реакция при комнатной температуре идет сравнительно медленно - в случае геранилхлорида около 20 суток ['], в случае фарнезилхлорида даже 30 суток [3]. Для ускорения реакции был использован метанол $\left[{ }^{4,5}\right]$. Попытки ускорить процесс путем повышения температуры в случае геранилхлорида не привели к желаемому результату из-за обратной диссоциации получаемого продукта при $65^{\circ} \mathrm{C}$ [1].

В настоящей работе изучена кинетика реакции алкоксиалкенилхлорида - 1-хлор-3-метил-5-изопропокси-2-пентена - c N, N-диметилфениламином. При этом были определены изменения концентраций исходного аллильного хлорида по ГЖХ и получаемых аммониевых солей по хлориону [ $\left.{ }^{1}\right]$. На рис. 1 приведены кривые кинетики при 30,40 и $50{ }^{\circ} \mathrm{C}$ и молярном соотношении алкоксиалкенилхлорид : N, N-диметилфениламин $1: 1,3$. В качестве ускорителя реакции использовали метанол $(1,4$ моля на 1 моль исходных хлоридов). Установлено, что при температуре 45$50{ }^{\circ} \mathrm{C}$ первичный аллильный хлорид, содержание которого в исходной фракции составляет $88,7-90 \%$, вступает в реакцию в количестве $90-$ $93,3 \%$ за 1,5-2 ч с образованием $97-99 \%$ четвертичных аммониевых солей от прореагировавших ингредиентов. Присутствующий третичный изомер - 3-метил-3-хлор-5-изопропокси-1-пентен - в условиях реакции дегидрохлорируется на $40-60 \%$. Кинетические данные реакции приведены в табл. 1.

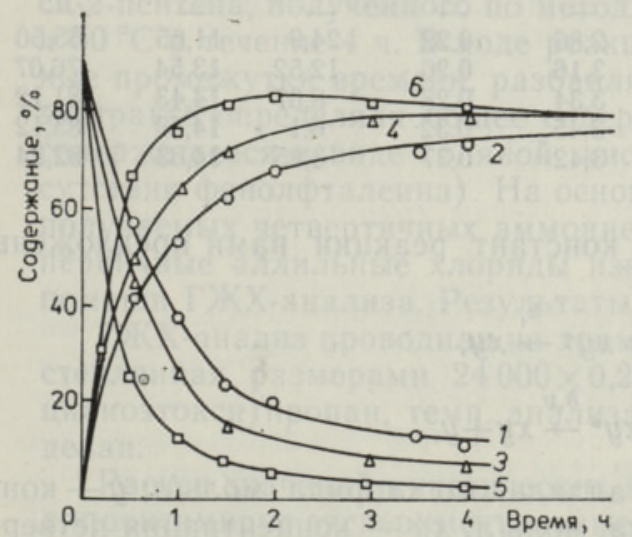

Рис. 1. Кинетика образования четвертичной соли $\left[\mathrm{C}_{9} \mathrm{H}_{17} \mathrm{OC}_{8} \mathrm{H}_{11} \mathrm{~N}\right]+\mathrm{Cl}^{-}$: изменение содержания исходного первичного $\mathrm{C}_{9} \mathrm{H}_{17} \mathrm{OCl}$ (1, $3,5)$ и конечной четвертичной аммониевой соли $(2,4,6)$ при $30^{\circ} \mathrm{C}(1,2), 40^{\circ} \mathrm{C}(3,4)$ и $50^{\circ} \mathrm{C}(5,6)$,

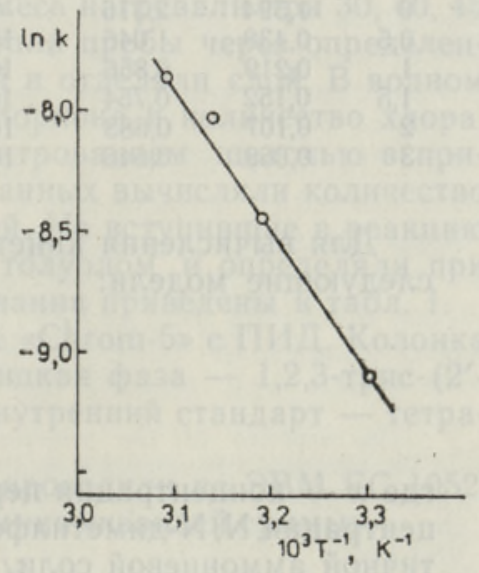

Рнс. 2. Зависимость константы скорости от температуры, 
Кинетика образования четвертичной аммониевой соли

\begin{tabular}{|c|c|c|c|c|c|c|c|c|}
\hline \multirow[b]{2}{*}{ 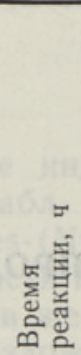 } & \multicolumn{2}{|c|}{$\begin{array}{c}\text { Концентрация } \\
\text { исходных реаген- } \\
\text { тов, моль/л }\end{array}$} & \multicolumn{3}{|c|}{ Водный раствор } & \multirow{2}{*}{ 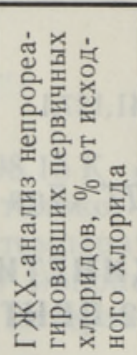 } & \multirow{2}{*}{ 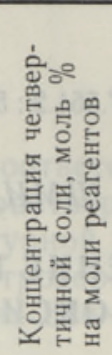 } & \multirow{2}{*}{ 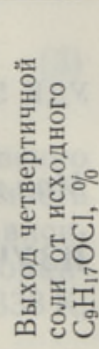 } \\
\hline & 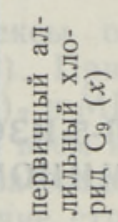 & 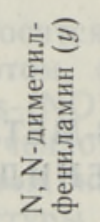 & $\begin{array}{c}\text { Bec, } \\
\text { г }\end{array}$ & ${ }_{\%}^{-}$ & $\underset{\%}{\mathrm{HCl}}$ & & & \\
\hline
\end{tabular}

Температура реакции $30^{\circ} \mathrm{C}$

$\begin{array}{lll}0 & 1,594 & 2,316 \\ 0,5 & 0,924 & 1,589 \\ 1 & 0,660 & 1,314 \\ 1,5 & 0,429 & 1,114 \\ 2 & 0,363 & 1,002 \\ 3,5 & 0,257 & 0,960 \\ 4 & 0,185 & 0,901\end{array}$

$\begin{array}{ll}\overline{13}, 9 & \overline{1,76} \\ 14,9 & 2,35 \\ 15,3 & 2,79 \\ 15,6 & 2,86 \\ 16,1 & 2,91 \\ 15,69 & 3,08\end{array}$

$\overline{0,13}$
0,14
0,15
0,15
0,16
0,18

\begin{tabular}{lrr}
$\overline{53,0}$ & \multicolumn{1}{c}{$\mathbf{6 , 6 9}$} & $\overline{38,25}$ \\
37,12 & 9,43 & 53,51 \\
24,66 & 11,33 & 64,32 \\
20,58 & 12,30 & 69,10 \\
14,69 & 12,56 & 71,26 \\
10,61 & 13,30 & 74,90
\end{tabular}

Температура реакции $40^{\circ} \mathrm{C}$

$\begin{array}{lll}0 & 1,643 & 2,336 \\ 0,5 & 0,757 & 1,388 \\ 1 & 0,472 & 1,079 \\ 1,5 & 0,259 & 0,904 \\ 3 & 0,132 & 0,776 \\ 4 & 0,126 & 0,745\end{array}$

$\overline{14,1}$
14,9
15,5
15,8
16,0

2,11
2,65
2,93
3,13
3,23

-17
0,20
0,23
0,27
0,31

$\begin{array}{rrr}\overline{43,0} & \overline{8,72} & \overline{49,73} \\ 26,68 & 11,45 & 64,37 \\ 14,62 & 13,12 & 73,17 \\ 7,54 & 14,3 & 78,28 \\ 7,20 & 14,59 & 79,23\end{array}$

Температура реакции $45^{\circ} \mathrm{C}$

$\begin{array}{lll}0 & 1,594 & 2,316 \\ 0,5 & 0,475 & 1,086 \\ 1 & 0,251 & 0,859 \\ 1,5 & 0,159 & 0,803 \\ 2 & 0,119 & 0,710 \\ 3,5 & 0,082 & 0,682\end{array}$

$-15,5$
16,0
16,0
17,0
16,5

$\begin{array}{ll}\overline{2,86} & \overline{0,19} \\ 3,15 & 0,21 \\ 3,27 & 0,23 \\ 3,28 & 0,22 \\ 3,34 & 0,29\end{array}$

$\begin{array}{ccl}\overline{26,83} & 1 \overline{11,96} & \overline{66,0} \\ 14,22 & 13,48 & 75,60 \\ 9,0 & 14,37 & 80,75 \\ 6,75 & 14,90 & 83,72 \\ 4,5 & 14,82 & 83,22\end{array}$

Температура реакции $50^{\circ} \mathrm{C}$

$\begin{array}{lllllllll}0 & 1,594 & 2,316 & \overline{-} & - & - & - & - & - \\ 0,5 & 0,438 & 1,046 & 15,65 & 2,86 & 0,22 & 24,9 & 11,65 & 65,50 \\ 1 & 0,219 & 0,856 & 16,05 & 3,16 & 0,26 & 12,52 & 13,54 & 76,07 \\ 1,5 & 0,152 & 0,754 & 16,25 & 3,34 & 0,28 & 8,67 & 14,43 & 81,12 \\ 2 & 0,107 & 0,683 & 16,4 & 3,45 & 0,32 & 6,1 & 14,79 & 83,12 \\ 3 & 0,068 & 0,646 & 16,6 & 3,42 & 0,37 & 3,85 & 14,63 & 82,24\end{array}$

Для вычисления кинетических констант реакции нами предложены следующие модели:

$$
\begin{gathered}
x+y \stackrel{k_{2}}{\rightleftarrows} x y^{*} \stackrel{k_{1}}{\rightarrow} x y, \\
x+y \stackrel{k_{2}}{\rightleftarrows} x y^{*} \stackrel{k_{1} y}{\rightarrow} x y+y,
\end{gathered}
$$

где $x$ - концентрация первичного аллильного хлорида, моль/л; $y-$ концентрация N, N-диметилфениламина, моль/л; $x y$ - концентрация четвертичной аммониевой соли, моль/л; $x y^{*}$ - концентрация активированного промежуточного комплекса, моль/л.

Кинетические уравнения и константы скорости приведены в табл. 2. При аппроксимации экспериментальных данных на ЭВМ установлена наибольшая вероятность уравнения (3), которая показывает, что реакция имеет по галогенопроизводному первый порядок и по амину второй. 
Кинетические константы и суммы квадратных отклонений

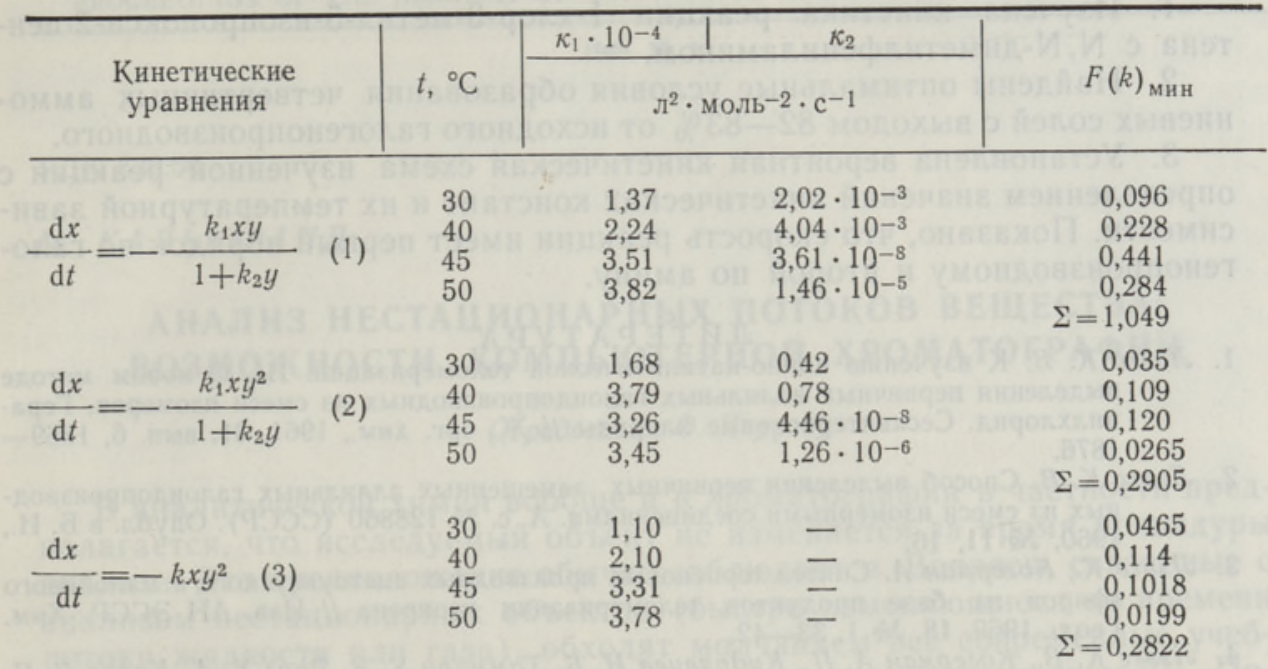

Это указывает, что концентрация равновесного промежуточного реакционного комплекса $\left(x y^{*}\right)$ является незначительной и может не учитываться.

На рис. 2 показана зависимость вычисленных констант скорости от температуры в виде $\ln k=f(1 / T)$, удовлетворительно укладывающаяся в линейную зависимость, из которой вычислено:

$$
k=1,28 \cdot 10^{5} \exp (-6323 / T), \pi^{2} \cdot \text { моль }^{-2} \cdot \mathrm{c}^{-1} .
$$

Полученные данные показывают, что повышение температуры на $10^{\circ} \mathrm{C}$ ускоряет скорость данной реакции в $1,8-1,9$ раза.

\section{Экспериментальная часть}

В трехгорлую колбу, снабженную мешалкой, обратным холодильником и термометром, загружали 22,5 г (0,186 моля) N, N-диметилфениламина, 10 г толуола, 15 г метанола и 25 г (0,128 моля - рассчитано на первичный хлорид) алкоксихлорида $\mathrm{C}_{9}-1$-хлор-3-метил-5-изопропокси-2-пентена, полученного по методике [ ${ }^{6}$. Смесь нагревали при 30, 40, 45 и $50{ }^{\circ} \mathrm{C}$ в течение 4 ч. В ходе реакции отбирали пробы через определенные промежутки времени, разбавляли водой и отделяли слой. В водном экстракте определяли общее содержание хлориона и количество хлора, содержащееся в виде соляной кислоты (титрованием щелочью в присутствии фенолфталеина). На основе этих данных вычисляли количество получаемых четвертичных аммониевых солей. Не вступившие в реакцию первичные аллильные хлориды извлекали толуолом и определяли при помощи ГЖХ-анализа. Результаты исследования приведены в табл. 1 .

ГЖХ-анализ проводили на хроматографе «Chrom-5» с ПИД. Колонка стеклянная размерами $24000 \times 0,27$ мм, жидкая фаза - 1,2,3-трис- $\left(2^{\prime}\right.$ цианоэтокси) пропан, темп. анализа $60^{\circ} \mathrm{C}$, внутренний стандарт - тетрадекан.

Расчет значений кинетических констант проводили на ЭВМ ЕС 1052, аппроксимируя экспериментальные данные минимизацией суммы:

$$
F=\sum_{i}\left(\frac{x_{i}-\bar{x}_{i}}{x_{i}}\right)^{2},
$$

где $x_{i}$ - опытные, $\bar{x}_{i}-$ расчетные данные. Поиск минимума осуществляли методом Розенброка (см, табл. 2). 


\section{Выводы}

1. Изучена кинетика реакции 1-хлор-3-метил-5-изопропокси-2-пентена с $\mathrm{N}, \mathrm{N}$-диметилфениламином.

2. Найдены оптимальные условия образования четвертичных аммониевых солей с выходом $82-83 \%$ от исходного галогенопроизводного.

3. Установлена вероятная кинетическая схема изученной реакции с определением значений кинетических констант и их температурной зависимости. Показано, что скорость реакции имеет первый порядок по галогенопроизводному и второй по амину.

\section{ЛИ ТЕ Р А Т У Р А}

1. Лээтс K. В. К изучению ионно-каталитической теломеризации. III. О новом методе выделения первичных аллильных галондопронзводных из смеси изомеров. Геранилхлорид. Сесквитерпеновые хлориды // Ж. орг. хим., 1961, 31, вып. 6, 1869 1876.

2. Лээтс К. В. Способ выделения первичных замещенных аллильных галоидопроизводных из смеси изомерными соединениями. А. с. № 128860 (СССР). Опубл. в Б. И., 1960, № 11, 16.

3. Лээтс K., Когерман А. Синтез терпеновых производных ацетоуксусного и малонового эфиров на базе продуктов теломеризации изопрена // Изв. АН ЭССР. Хим. Геол., 1969, 18, № 1, 33-42.

4. Лээтс К. В., Когерман А. П., Кудрявцев И. Б., Таммару У. Э., Ранг Х. А., Краав Л. П. Способ выделения $\beta$-непредельных первичных хлоралкилов. А. с. № 582241 (СССР). Опубл. в Б. И., 1977, № 44, 83.

5. Лээтс К., Когерман А., Аммон К., Таммару У., Кудрявцев И. Изучение влияния некоторых растворителей на скорость реакции фарнезилхлорида с N, N-диметиланилином // Изв. АН ЭССР. Хим., 1979, 28, № 3, 212-213.

6. Лээтс K., Каал T., Шмидт М., Кудрявцева К. Влияние природы катализатора на теломеризацию изопрена с $\alpha$-хлорметилизопропиловым эфиром // Изв. АН ЭССР. Хим., 1980, 29, № 3, 232-234.

Ннститут химии

Академии наук Эстонской ССР
Поступила в редакцию 29/VI 1988

Malle SCHMIDT, Lïa KRUMM, K. LÃ̆TS

\section{1-KLOOR-3-METOOL-5-ISOPROPOKSU-2-PENTEENI JA N,N-DIMETUOLFENUOLAMIINI VAHELISE REAKTSIOONI KINEETIKA UURIMINE}

On uuritud reaktsiooni kineetikat temperatuuridel $30,40,45$ ja $50^{\circ} \mathrm{C}$, leitud optimaalsed tingimused kvaternaarse ammooniumisoola tekkeks, selgitatud välja kõige tõenäolisem reaktsiooni skeem ja arvutatud kiiruskonstandi sōltuvus temperatuurist.

Malle SCHMIDT, Liia KRUMM, K. LAATS

\section{INVESTIGATION OF THE KINETICS OF THE REACTION OF 1-CHLORO-3-METHYL-5-ISOPROPOXY-2-PENTENE WITH N,N-DIMETHYLPHENYLAMINE}

The kinetics of the reaction between allylchloride and $\mathrm{N}, \mathrm{N}$-dimethylphenylamine in the presence of methanol at $30,40,45$ and $50^{\circ} \mathrm{C}$ has been studied. The most probable reaction scheme to describe the reaction has been found out. An equation for estimating the reaction rate in dependence on temperature with the values of kinetic constants is presented. 